\title{
Energy conservation technique improves dyspnoea when patients with severe COPD climb stairs: a randomised crossover study
}

\author{
Guillaume Prieur, ${ }^{1,2,3}$ Yann Combret (D) , 1,3 Clement Medrinal, ${ }^{2,3}$ Nathalie Arnol, ${ }^{4}$ \\ Tristan Bonnevie (D) , 2,5 Francis-Edouard Gravier, ${ }^{2,5}$ Jean Quieffin, ${ }^{3}$ Bouchra Lamia, ${ }^{2,3}$ \\ Gregory Reychler, ${ }^{1,6}$ Jean-Christian Borel (1) 7,8
}

- Additional material is published online only. To view please visit the journal online (http://dx.doi.org/10.1136/ thoraxjnl-2019-214295).

1 Institute of Experimental and Clinical Research (IREC) Pole of Pulmonology, ORL and Dermatology, Université catholique de Louvain, 1200, Belgium

${ }^{2}$ Normandie Univ, UNIROUEN, EA3830-GRHV, Institute for Research and Innovation in Biomedicine (IRIB), 76000

Rouen, France

${ }^{3}$ Pulmonology department and pulmonary rehabilitation department, Groupe Hospitalier du Havre, 76290 Montivilliers, France

${ }^{4}$ ICADOM, AGIR à dom, Meylan, France

${ }^{5}$ ADIR Association, Bois-

Guillaume, France

${ }^{6}$ Department of Pneumology,

Cliniques universitaires Saint

Luc, Brusels, Belgium

${ }^{7} R \& D, A G I R$ à dom, Meylan, France

${ }^{8} \mathrm{HP} 2$ Laboratory INSERM U1042, Grenoble University, Grenoble, France

\section{Correspondence to} Guillaume Prieur, Pulmonology department, Groupe Hospitalier du Havre, 76290 Montivilliers, France; gprieur.kine@gmail.com

Received 5 November 2019 Revised 24 February 2020

Accepted 28 February 2020 Published Online First 26 March 2020

\section{Check for updates}

(C) Author(s) (or their employer(s)) 2020. No commercial re-use. See rights and permissions. Published by BMJ.

To cite: Prieur G, Combret Y, Medrinal C, et al. Thorax 2020:75:510-512.

\section{ABSTRACT}

In this randomised, crossover trial, 22 patients with severe chronic obstructive pulmonary disease climbed six flights of stairs (108 steps) twice, under two test conditions: (1) energy conservation technique (ECT): participants were asked to rest for at least 5 seconds every three steps and (2) control condition: participants climbed the stairs at their own pace. Significant lower dyspnoea (primary outcome), leg discomfort, minute ventilation and capillary blood lactate under the ECT condition were found, with no change in total task time. Clinical trial registration NCT03564028

\section{INTRODUCTION}

Stair-climbing is reported as a frequent problem by individuals with chronic obstructive pulmonary disease (COPD). ${ }^{1-3}$ These individuals often actively avoid stair-climbing, which can lead to social isolation. ${ }^{4} \mathrm{~A}$ technique that could help these individuals to climb stairs is energy conservation technique (ECT) by fractionating this task. ${ }^{56}$

We hypothesised that by fractionating the effort during stair-climbing, individuals with severe COPD and functional dyspnoea would experience less dyspnoea.

\section{METHODS}

\section{Study design and participants}

This randomised, crossover, single-centre trial (Pulmonary rehabilitation unit; Groupe Hospitalier du Havre) was prospectively registered on ClinicalTrials.Gov (NCT03564028).

The inclusion criteria were as follows: diagnosis of COPD in accordance with the global initiative for chronic obstructive lung disease (GOLD) recommendations and with functional dyspnoea (modified medical research council scale $\geq 2$ ).

The exclusion criteria were as follows: cardiovascular contraindications to exercise or being incapable of climbing six flights of stairs in less than $15 \mathrm{~min}$. A maximal duration of $15 \mathrm{~min}$ was arbitrarily chosen as a cut-off limit for participation. We considered that patients who were this severely deconditioned would likely be unable to complete the whole protocol.

\section{Intervention}

Participants were asked to climb six flights of stairs (108 steps, $16 \mathrm{~cm}$ high, $30 \mathrm{~cm}$ long) twice under two different conditions (control and ECT) separated by $30 \mathrm{~min}$ of rest, in a randomised order.

In the control condition, participants were asked to climb the six flights of stairs at their own pace. They were told they could 'rest as needed'.

For the ECT condition, participants were asked to rest for at least 5 seconds after each three steps. If they wished, the rest could be longer.

No encouragement was given in both conditions. The interventions were separated by $30 \mathrm{~min}$ of strict rest. Patients using oxygen therapy carried their usual portable oxygen on their shoulders. The physiotherapist supervising the intervention remained behind the participants as they climbed to avoid influencing their efforts.

\section{Outcome measures}

The primary outcome was end-of-task dyspnoea measured using the modified 0-10 Borg scale.

Secondary outcomes were as follows: leg discomfort (modified Borg scale); pulsed oxygen saturation $\left(\mathrm{SpO}_{2}\right)$; heart rate $(\mathrm{HR})$; respiratory rate (RR); oxygen saturation of the vastus lateralis muscle (StO2); minute ventilation (Ve) and inspiratory capacity; capillary blood lactate; time taken to climb the six flights and the number of rests (defined as $\geq 10$ s). $\mathrm{SpO}_{2}, \mathrm{HR}, \mathrm{RR}$ and $\mathrm{StO}_{2}$ were continuously recorded during the test. Other outcomes were measured at the beginning and the end of the exercise. Information is available in online supplementary data.

\section{Randomisation and blinding}

The order of the conditions was randomised by the research unit using computer software Edgar2 (http://www.edgarweb.org.uk/) with a ratio of $1: 1$. The test sequence (in a sealed, opaque envelope with the inclusion number) was given to the investigator before the start of the first test condition. The inputting of data into the database and statistical analysis were carried out under blind conditions.

\section{Statistical analysis}

In all, 22 participants were required (mean difference in dyspnoea of 2 points; SD 2 points: Power 90\%; alpha risk $\leq 0.05$ ) (see online supplementary file for details and comments). Data analysis was conducted using SAS V.9.4 software (Cary, NC, USA). Continuous data are presented as means (SD) (or means and 
Table 1 Baseline characteristics of the 22 patients

\begin{tabular}{|c|c|}
\hline & All $(n=22)$ \\
\hline Sex (men), n (\%) & $12(54.5)$ \\
\hline Age & $63(60 ; 66)$ \\
\hline $\mathrm{BMI}, \mathrm{kg} / \mathrm{m}^{2}$ & $25.1(6.3)$ \\
\hline Smoking history, pack years & $40(22)$ \\
\hline LTOT, n (\%) & $5(22.7)$ \\
\hline \multicolumn{2}{|l|}{ Lung function } \\
\hline FEV1, \% pred & $32(27 ; 47)$ \\
\hline FVC, \% pred & $79(18)$ \\
\hline FEV1/FVC, \% & $37.7(11.1)$ \\
\hline TLC, \% pred & $112(22)$ \\
\hline $\mathrm{RV}, \%$ pred & $178(147 ; 205)$ \\
\hline VR/TLC, \% & $58.2(7.5)$ \\
\hline DLCO, \% pred & $46(20)$ \\
\hline \multicolumn{2}{|l|}{ Arterial blood gases (at rest) } \\
\hline $\mathrm{PaO}_{2}, \mathrm{kPa}$ & $9.5(1.3)$ \\
\hline $\mathrm{PaCO}_{2^{\prime}} \mathrm{kPa}$ & $6.0(1.1)$ \\
\hline $\mathrm{pH}$ & $7.42(0.03)$ \\
\hline $\mathrm{HCO}_{3} ; \mathrm{mmol} / \mathrm{L}$ & $27.5(26.8 ; 29.4)$ \\
\hline $\mathrm{SaO}_{2}, \%$ & $94.3(2.7)$ \\
\hline \multicolumn{2}{|c|}{ Functional capacity and health status } \\
\hline 6MWT (m) & $406(101)$ \\
\hline \multicolumn{2}{|l|}{ mMRC score } \\
\hline $\mathrm{mMRC} 2, \mathrm{n}(\%)$ & $9(40.9)$ \\
\hline mMRC 3, n (\%) & $12(54.5)$ \\
\hline mMRC 4, n (\%) & $1(4.5)$ \\
\hline \multicolumn{2}{|l|}{ HAD score } \\
\hline Anxiety & $9(5)$ \\
\hline Depression & $7(4)$ \\
\hline \multicolumn{2}{|l|}{ SGRQ (\% maximum) } \\
\hline Symptoms & $51(43 ; 62)$ \\
\hline Activities & $72(17)$ \\
\hline Impacts & $38(15)$ \\
\hline Total score & 50 (14) \\
\hline
\end{tabular}

Mean (SD) or Median (25th;75th).

Arterial blood gases were collected on room air for patients who were normoxic at rest and under oxygen for patients with LTOT.

$\mathrm{BMI}$, body mass index; DLCO, carbon monoxide transfer factor; F, female; FEV1, forced expiratory volume in one second; FVC, forced vital capacity; HAD, Hospital Anxiety Depression Scale; LTOT, long-term oxygen therapy; M, male; mMRC, modified Medical Research Council scale; 6MWT, Six Min Walk Test; PaC02, arterial partial pressure of carbon dioxide; $\mathrm{PaO2}$, arterial partial pressure of oxygen; $\mathrm{RV}$, residual volume; SaO2, arterial oxygen saturation; SGRQ, St George's Respiratory Questionnaire; TLC, total lung capacity.

95\% CI for the difference between the two conditions) or medians (Q1; Q3) depending on the normality of the distribution (ShapiroWilk test). A treatment effect test (adjusted for period), a period effect test (adjusted for treatment) and a test for the interaction between treatment and period were successively used to assess the respective effect of treatment, treatment sequence and the firstorder carryover risk. These three effects were analysed using a Student t-test or a Mann-Whitney test according to the distribution of the data (the specific calculations used for the crossover analysis are detailed in the supplementary data. ${ }^{7}$ Changes within each of the conditions were compared using a paired t-test or a Wilcoxon test, depending on the normality of the distribution. In the case of a significant interaction between treatment and period (first-order carryover risk), only the first sequence was analysed.

Intention-to-treat analysis (with imputation of the missing data by the median value of the opposite condition for a given variable) was carried out.

\section{RESULTS}

Between July 2018 and April 2019, 52 patients were admitted to our department for pulmonary rehabilitation. Of these, 23 were eligible for participation, 1 declined to participate (online supplementary figure 1), thus 22 were included (median, $(\mathrm{IQR})$ age $=63(60 ; 66)$ years and FEV1=32 $(27 ; 47) \%$ of predicted value). The baseline characteristics of the participants are presented in table 1.

The values of the intention-to-treat analysis are provided in table 2. The $\mathrm{p}$ values of the interaction between condition and order are presented in online supplementary table 1 . The level of dyspnoea was significantly lower at the end of the task in the ECT test condition compared with the control condition (median between conditions differences $=-1.00(-3.50$; -1.00 )) (table 2, figure 1, online supplementary figure S2).

Leg discomfort was significantly lower in the ECT condition (table 2, figure 1, online supplementary figure 3). Capillary blood lactate, VE, total rest time (rests of $\geq 10$ s) were also significantly lower in the ECT condition (table 2, figure 1).

There were no differences in outcomes between test conditions for total task time, $\mathrm{SpO} 2, \mathrm{StO} 2$ or RR (table 2).

All 22 participants reported feeling less breathlessness during the ECT condition and 14 preferred the ECT condition.

\section{DISCUSSION}

This is the first study to propose and evaluate an ECT for stairclimbing in patients with severe COPD with activity limitation and anxiety.

Physiological studies have shown that fractionated exercise helps to optimise aerobic metabolism by reducing oxygen consumption, lactate production and facilitating the partial restoration of phosphocreatine during the rest period. ${ }^{8}$ This reduces the ventilatory requirement, along with dyspnoea and muscle fatigue, leading to an improvement in exercise tolerance in individuals with severe COPD. ${ }^{8}$ In our study, the change in ventilatory pattern with a reduction in minute ventilation at the end of the task could explain the improvement in symptoms and the need for long rests with the ECT. Although the total standardised rest time could be longer when climbing stairs using an ECT ( $5 \mathrm{~s}$ rest every three steps), the total time to climb the stairs is not necessarily longer. This information can be useful in terms of patient education. The carryover effect observed for the total test time demonstrates that the technique should be adapted to the severity of the patient's condition: patients with milder conditions might benefit from less frequent or shorter rests. Further studies are required to evaluate (i) if this ECT ( $5 \mathrm{~s} / 3$ steps) is appropriate for real life or if the ratio (rest time/number of steps) should be modified to facilitate its use and (ii) if the ECT reduce their apprehension in relation to stair-climbing. ${ }^{34}$

\section{CONCLUSION}

The application of an ECT to a stair-climbing task significantly reduced dyspnoea without affecting the time taken to complete the task in individuals with severe COPD. 
Table 2 Effects of energy conservation technique condition versus control condition on breathlessness and physiological variables at the end of exercise (intention-to-treat analysis)

\begin{tabular}{|c|c|c|c|c|c|c|}
\hline \multirow[b]{2}{*}{ Variables } & \multicolumn{2}{|c|}{ Energy conservation technique } & \multicolumn{2}{|l|}{ Control } & \multicolumn{2}{|l|}{ Condition effect } \\
\hline & Baseline & End-exercise & Baseline & End-exercise & $\begin{array}{l}\text { Between conditions differences }(95 \% \\
\mathrm{Cl}) \text { or }(25 \mathrm{th} ; 75 \mathrm{th})\end{array}$ & $P$ value \\
\hline Breathlessness (mBorg) & $0.0(0.0 ; 0.5)$ & $3.0(2.0 ; 4.0)^{* * *}$ & $0.0(0.0 ; 1.0)$ & $5.0(4.0 ; 6.0)^{* * *}$ & $-1.00(-3.50 ;-1.00)$ & $<0.001$ \\
\hline Leg discomfort (mBorg) & $0.0(0.0 ; 0.0)$ & $2.0(0.0 ; 2.0)^{* * *}$ & $0.0(0.0 ; 0.0)$ & $3.0(2.0 ; 5.0)^{* * *}$ & $-1.00(-3.00 ; 0.00)$ & 0.006 \\
\hline Sp02 (\%) & $92.8(3.5)$ & $85.3(6.3)^{* * *}$ & $93.1(3.2)$ & $84.8(7)^{\star * *}$ & $0.53(-1.54 ; 2.61)$ & 0.6 \\
\hline St02 (\%) & $66.0(6.1)$ & $57.8(9.6)^{*}$ & $67.9(6.3)$ & $57.2(8.3)^{* * *}$ & $2.18(-0.63 ; 4.99)$ & 0.12 \\
\hline Heart rate (bpm) & $85.5(12.3)$ & $108.0(13.6)$ & $86.7(17.3)$ & $103.9(22.2)$ & $5.26(-6.01 ; 16.53)$ & 0.34 \\
\hline Respiratory rate (cpm) & $20.0(18.0 ; 22.0)$ & $27.0(23.0 ; 30.0)^{* * *}$ & $20.5(18.0 ; 22.0)$ & $28.0(26.0 ; 32.0)^{* * *}$ & $-1.00(-4.00 ; 1.00)$ & 0.14 \\
\hline Minute ventilation (L/min) & $11.2(3.5)$ & $19.1(6.7)^{* * *}$ & $10.9(3.8)$ & $27.6(8.6)^{* * *}$ & $-8.68(-12.00 ;-5.37)$ & $<0.001$ \\
\hline Inspiratory capacity (L) & $1.8(0.6)$ & $1.7(0.5)^{*}$ & $1.9(0.7)$ & $1.5(0.5)^{*}$ & $0.14(-0.02 ; 0.31)$ & 0.08 \\
\hline Lactate (mmol/L) & $2.1(1.8 ; 2.7)$ & $2.9(2.0 ; 3.4)^{* *}$ & $1.5(1.4 ; 2.0)$ & $4.5(3.5 ; 6.1)^{* * *}$ & $-2.30(-3.90 ;-1.10)$ & 0.013 \\
\hline $\begin{array}{l}\text { Number of breaks (defined as } \\
\text { break } \geq 10 \mathrm{~s} \text { ) } 0.0410\end{array}$ & - & $0.0(0.0 ; 0.0)$ & - & $3.0(1.0 ; 4.0)$ & - & $<0.001$ \\
\hline Total duration of breaks (s) & - & $0.0(0.0 ; 0.0)$ & - & $54.0(10.0 ; 140.0)$ & $-54.00(-136.00 ; 0.00)$ & $<0.001$ \\
\hline Total task time (s) & - & $372.5(73.0)$ & - & $341.6(128.5)$ & $30.91(-58.64 ; 120.50)$ & 0.48 \\
\hline
\end{tabular}

Continuous data are presented as means (SD) (or means and $95 \% \mathrm{Cl}$ for the difference between the two conditions) or medians (01; 03) depending on the normality of the distribution. Effect of intervention, intervention sequence and the first-order carryover risk were analysed using a Student's t-test or a Mann-Whitney test, depending on the normality of the distribution. Changes within each of the conditions were compared using a paired t-test or a Wilcoxon test, depending on normality.

$\mathrm{mBorg}$, modified Borg scale from 0 to 10 (0: no fatigue or dyspnoea, 10: maximal effort); Sp02, pulsed 02 saturation. For HR, the median number of breaks taken during test and the total task time, there were a significant interactions with the order of the conditions tested (respectively $p=0.0480$ for $\mathrm{HR}, \mathrm{p}=0.0410$ for the median number of breaks and $p=0.0158$ for total task time); therefore, only the first sequence was analysed in each case.

${ }^{*} \mathrm{p}<0.05$ for before-after analysis of a condition; ${ }^{* *} \mathrm{p}<0.01$ for before-after analysis of a condition; ${ }^{* * *} \mathrm{p}<0.001$ for before-after analysis of a condition.

Acknowledgements We thank Johanna Robertson and Mark Tawileh for translation and constructive criticism. We also thank all patients for their patience and for agreeing to participate in this study. We also thank Remi Mazars and Thomas Bunel for the inputting of data into the database.

Contributors Trial concept and design: GP, CM, YC, JCB and GR; acquisition of

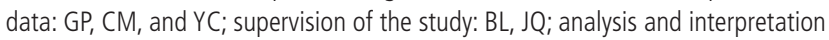
of data: NA, GP, GR and JCB, drafting the article: GP, CM, YC, TB, FEG, JCB and
A

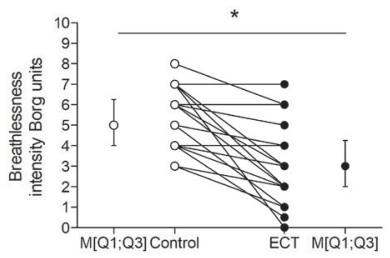

C

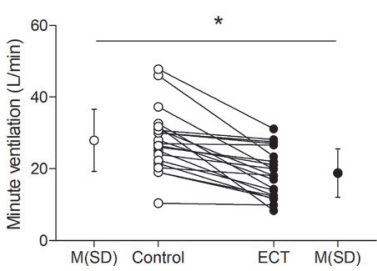

B

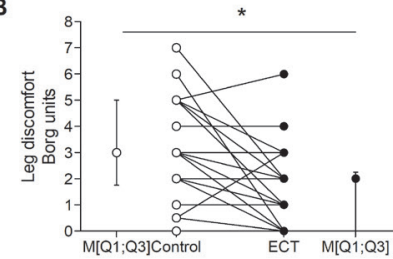

D

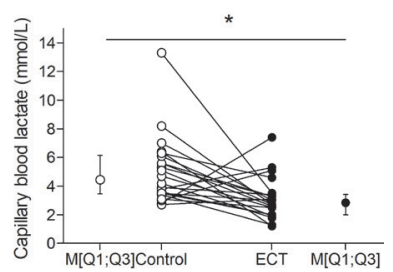

Figure 1 (A) Breathlessness; (B) leg discomfort; (C) minute ventilation; (D) capillary blood lactate at the end of the task in the ECT condition versus the control condition during the ascension of 108 steps (six flights). Data in panels A, B and D are presented as individual data and medians (25th;75th). Data in panel $C$ are presented as individual data and mean \pm standard deviation. ${ }^{*} \mathrm{p}<0.05$. ECT, energy conservation technique
GR; revising it critically for important intellectual content and final approval of the version to be published: all authors. GP had full access to all trial data and takes responsibility for the integrity of the data and the accuracy of the data analysis.

Funding This work was supported by GHAHR Association (Le Havre, France).

Competing interests None declared.

Patient consent for publication Not required.

Ethics approval This study was approved by the French Ethics committee Est I (April 26 2018). Written informed consent was obtained from all patients.

Provenance and peer review Not commissioned; externally peer reviewed.

\section{ORCID iDs}

Yann Combret http://orcid.org/0000-0003-1962-3331

Tristan Bonnevie http://orcid.org/0000-0003-0550-813X

Jean-Christian Borel http://orcid.org/0000-0003-4140-6210

\section{REFERENCES}

1 Annegarn J, Meijer K, Passos VL, et al. Problematic activities of daily life are weakly associated with clinical characteristics in COPD. J Am Med Dir Assoc 2012;13:284-90.

2 van Helvoort HA, Willems LM, Dekhuijzen PR, et al. Respiratory constraints during activities in daily life and the impact on health status in patients with early-stage COPD: a cross-sectional study. NPJ Prim Care Respir Med 2016;26:16054.

3 Martinsen U, Bentzen $\mathrm{H}$, Holter MK, et al. The effect of occupational therapy in patients with chronic obstructive pulmonary disease: a randomized controlled trial. Scand I Occup Ther 2017;24:89-97.

4 Elkington $\mathrm{H}$, White $\mathrm{P}$, Addington-Hall J, et al. The last year of life of COPD: a qualitative study of symptoms and services. Respir Med 2004;98:439-45.

5 Velloso M, Jardim JR. Study of energy expenditure during activities of daily living using and not using body position recommended by energy conservation techniques in patients with COPD. Chest 2006;130:126-32.

6 Silva CS, Nogueira FR, Porto EF, et al. Dynamic hyperinflation during activities of daily living in COPD patients. Chron Respir Dis 2015;12:189-96.

7 Hills M, Armitage P. The two-period cross-over clinical trial. Br J Clin Pharmacol 1979;8:7-20.

8 Kortianou EA, Nasis IG, Spetsioti ST, et al. Effectiveness of interval exercise training in patients with COPD. Cardiopulm Phys Ther J 2010;21:12-19. 